Article

\title{
Green aerobic oxidative desulfurization of diesel by constructing an Fe-Anderson type polyoxometalate and benzene sulfonic acid-based deep eutectic solvent biomimetic cycle
}

\author{
Jiajia Xu a , Zhiguo Zhu a, Ting Su a, Weiping Liao a, Changliang Deng a, Dongmei Hao a,b,\#, \\ Yuchao Zhao a,c, Wanzhong Ren c, Hongying Lü a,* \\ a Green Chemistry Centre, College of Chemistry and Chemical Engineering, Yantai University, Yantai 264005, Shandong, China \\ b School of Civil Engineering, Yantai University, Yantai 264005, Shandong, China \\ ${ }^{\mathrm{c}}$ Collaborative Innovation Center of Light Hydrocarbon Transformation and Utilization, College of Chemistry and Chemical Engineering, Yantai Universi- \\ ty, Yantai, 264005, Shandong, China
}

\section{A R T I C L E I N F O}

\section{Article history:}

Received 12 November 2019

Accepted 14 Decmeber 2019

Published 5 May 2020

\section{Keywords:}

Aerobic oxidative desulfurization

Fe-Anderson type polyoxometalate

Deep eutectic solvents

Dibenzothiophene

Physical characteristics

Electron transfer mediators

\begin{abstract}
A B S T R A C T
A unique redox-coupled biomimetic system was developed, in which Fe-Anderson type polyoxometalates (POMs) were employed as electron transfer mediators (ETMs) and benzenesulfonic acid (BSA)-based deep eutectic solvents (DESs) were used as electron-donors for aerobic oxidative desulfurization (AODS) of diesel fuel. Different compositions of DESs were used and the polyethylene glycol 2000 (PEG2000)/2.5BSA system showed the highest desulfurization activity, with the removal of dibenzothiophene (DBT) at $60{ }^{\circ} \mathrm{C}$ reaching $95 \%$ in $60 \mathrm{~min}$. The excellent desulfurization activity of the system is due to the in situ formation of peroxysulfonate via a biomimetic process. By constructing a coupled redox system, Fe-Anderson type POMs as ETMs reduce the activation energy of oxygen-activated sulfonate. The physical characteristics of four different DESs were tested. The results show that the conductivity of DESs is correlated with the composition of BSA-based DESs. However, there is no similar trend in viscosity testing at the same temperature, and the maximum viscosity value is obtained for the PEG2000/2.5BSA system at $60^{\circ} \mathrm{C}$, which may be associated with the stronger hydrogen bonds. It is worth noting that the PEG2000/2.5BSA system also possesses the best desulfurization activity, which suggests that the activity of the desulfurization system is related to the strength of the hydrogen bond in DESs. Finally, the biomimetic desulfurization system exhibits excellent performance and good stability under mild reaction conditions $\left(60^{\circ} \mathrm{C}\right.$, atmospheric pressure, oxygen as the oxidant).
\end{abstract}

(C) 2020, Dalian Institute of Chemical Physics, Chinese Academy of Sciences. Published by Elsevier B.V. All rights reserved.

\section{Introduction}

In the past few decades, there has been a growing concern about the environmental pollution issue. The sulfur compounds in diesel can be transformed into $\mathrm{SO}_{x}$ upon burning, causing serious environmental pollution [1,2]. Therefore, the production of fuels with very low levels of sulfur compounds is a grand challenge for diesel producers to meet stringent national requirements. Hydrodesulfurization (HDS) has been regarded as the most efficient diesel desulfurization process to eliminate

\footnotetext{
* Corresponding author. Tel/Fax: +86-535-6902603; E-mail: hylv@ytu.edu.cn

\# Corresponding author. E-mail: qgzx@ytu.edu.cn

This work was supported by the National Natural Science Foundation of China (21676230 and 21373177).

DOI: S1872-2067(19)63500-X | http://www.sciencedirect.com/science/journal/18722067 | Chin. J. Catal., Vol. 41, No. 5, May 2020
} 
sulfides and disulfides, but is less effective for removing 4,6-dimethyldibenzothiophene and its derivatives with large molecular sizes. In addition, this process usually demands high temperature and pressure [3-6].

Oxidative desulfurization (ODS) is an alternative or supplementary system to HDS for deep desulfurization, which includes the oxidation of sulfides and the extraction separation of oxidation products. It is one of the most effective methods to dispose of aromatic sulfur compounds and their derivatives, and has drawn great attention $[7,8]$. Extractants include organic polar solvents, ionic liquids and DESs. Organic solvents have extremely strong volatility and toxicity, which are not conducive to the green, pollution-free development of desulfurization. Because of the shortcomings of organic solvents, the focus has shifted to more environmentally friendly solvents (ionic liquids and DESs) [9-14]. Recently, the use of ionic liquid extraction-oxidizing fuel to remove sulfur-containing compounds has been extensively studied because ionic liquids have many advantages as solvents (environmentally friendly, non-toxic) [3,15-17]. However, the drawbacks of ionic liquids, including valuableness, low biodegradability, and difficulties in purification, limit their further development. Widespread attention has been paid to much cheaper, green, and environment-friendly solvents (DESs) [18-20], which are liquids usually formed by hydrogen bonding interactions of two or three green and inexpensive constituents. Their physicochemical properties are similar to those of traditional ionic liquids, but they have the advantage of being cheap and biodegradable. Recently, the use of DESs as extractants and catalysts has been widely studied because of their special properties, non-toxicity and harmless characteristics [18-27].

In order to thoroughly remove refractory S-compounds, many types of oxidants have been tested, such as tert-butyl hydroperoxide, hydrogen peroxide $\left(\mathrm{H}_{2} \mathrm{O}_{2}\right)$, and ozone $\left(\mathrm{O}_{3}\right)$ $[17,28,29]$. ODS processes usually use $\mathrm{H}_{2} \mathrm{O}_{2}$ as a highly efficient oxidant since this has the advantages of low cost and no by-product formation [3,7,8,30-33]. However, $\mathrm{H}_{2} \mathrm{O}_{2}$ has low stability, being easily decomposed by light, heat, microwave rays, and tiny particles [7]. $\mathrm{H}_{2} \mathrm{O}_{2}$ is a liquid that is highly corrosive at room temperature and requires high-level equipment for transport, storage, and subsequent application. Moreover, $\mathrm{H}_{2} \mathrm{O}_{2}$ is not cheap relative to molecular oxygen.

Over the past few years, scientists have been working hard to find novel ways for aerobic oxidation desulfurization (AODS) to remove sulfur compounds from diesel. For instance, emulsion catalysis $\left[\mathrm{C}_{18} \mathrm{H}_{37} \mathrm{~N}\left(\mathrm{CH}_{3}\right)_{3}\right]_{5}\left[\mathrm{PV}_{2} \mathrm{Mo}_{10} \mathrm{O}_{40}\right]$ could achieve a $99 \%$ desulfurization rate at $60{ }^{\circ} \mathrm{C}$ in the presence of isobutyl aldehydes (sacrificial agents) under 1 bar $\mathrm{O}_{2}$ within $4 \mathrm{~h}$. However, the use of sacrificial agents limits its further application [34]. $\mathrm{H}_{5} \mathrm{PV}_{2} \mathrm{Mo}_{10} \mathrm{O}_{40} / \mathrm{SiO}_{2}$ afforded a desulfurization efficiency of $99 \%$ at $120{ }^{\circ} \mathrm{C}$ within $5 \mathrm{~h}$ under $1 \mathrm{~atm} \mathrm{O}_{2}$ [35]. In addition, Zhu and co-workers prepared a series of boron nitride (BN) material catalysts, which exhibit surprising catalytic activity. The sulfur compounds in diesel can be completely removed without using additives [36-38]. However, the disadvantage is that the desulfurization process needs to be carried out under high temperature conditions. A high-temperature desulfuriza- tion process leads to a decrease in oil quality, which is not conducive to further industrial applications. A liquid-liquid extraction and photochemical oxidative desulfurization system (EPODS) composed of air, isobutylaldehyde (IBA), DESs, and model oil was also assembled. The system achieved excellent desulfurization activity. The DBT removal rate could reach $96.3 \%$ at $30^{\circ} \mathrm{C}$ within $3 \mathrm{~h}$ with the sacrificial agent IBA [39]. In our previous work, we found that Anderson-type catalysts displayed excellent activities in desulfurization systems for oxidizing sulfur compounds in diesel to their corresponding sulfones using molecular oxygen as an oxidant without adding any sacrificial agents under mild conditions [40-42]. However, these homogeneous catalysts are difficult to be separated and recycled. Therefore, the development of an AODS system with high efficiency and simple recycling, in the absence of any sacrificial agents under mild conditions, remains an important challenge.

As a strong oxidant, peroxide sulfonate has been studied in the field of oxidation $[32,43,44]$. Schulz et al. [45] found that $p$-chlorotoluene peroxysulfonate formed in situ is highly selective in the oxidation reaction, preferentially attacking electron-rich atoms. Unfortunately, the conditions for the formation of peroxosulfonate are too harsh and usually require the presence of $\mathrm{H}_{2} \mathrm{O}_{2}$ and $\mathrm{OH}^{-}$. Recently, Piera et al. [46] have found that the activation energy of the direct oxidation of oxygen can be greatly reduced by a biomimetic path, thereby overcoming the kinetic disadvantages. The use of electron transfer mediators (ETMs) generally promotes the reaction by transporting electrons from the catalyst to the oxidant along a low energy pathway, thereby increasing oxidation efficiency. The transition metal Mo in the highest oxidation state is capable of forming metal-oxygen cluster anions, commonly referred to as polyoxometalates (POMs) [47]. The molecular and electronic structural diversities of these species are significant in biomimetic catalysis $[46,48,49]$. Therefore, the use of POMs as ETMs to generate peroxysulfonate in situ with molecular dioxygen is the focus of our research. In our previous work [50], Co polyanion catalysts and p-TsOH-based DESs which can oxidize sulfur compounds in diesel fuel by a biomimetic approach to corresponding sulfones were reported. Despite the great progress that has been made, the DES biomimetic system still has a lot of room for development. For example, the role of POMs in biological simulation systems has not been clearly stated. Establishing the relationship between the physicochemical properties of the eutectic mixtures and the oxidation desulfurization efficiency of the biomimetic system is more difficult. Therefore, solving the above problems is one of the most critical challenges to the highly desired development of a biomimetic process for AODS.

In this study, a biomimetic method was used to design a novel and efficient AODS system that can significantly improve the efficiency of ODS. An Anderson-type catalyst, $\mathrm{Na}_{3} \mathrm{Fe}(\mathrm{OH})_{6} \mathrm{Mo}_{6} \mathrm{O}_{18}$, was prepared by recrystallization and applied in an AODS system of diesel. An Fe-Anderson type POM, $\mathrm{Na}_{3} \mathrm{Fe}(\mathrm{OH})_{6} \mathrm{Mo}_{6} \mathrm{O}_{18}$, and BSA-based DESs were respectively used as the ETM and the electron donors to mimic the enzyme oxidation system. The AODS system exhibits outstanding cata- 
lytic activity. With $\mathrm{O}_{2}$ as the oxidant, the DBT removal can reach $95 \%$ at $60{ }^{\circ} \mathrm{C}$ in $60 \mathrm{~min}$. The effects of different catalysts, DES composition, and reaction conditions (reaction temperature, DES dosage, catalyst dose, S-compounds, commercial diesel, and catalytic system recycling) on desulfurization were studied.

\section{Experimental}

\subsection{Materials}

Poly(ethylene glycol) with average $M_{n}=2000$, ammonium molybdate tetrahydrate (AR, 99\%) and sodium molybdate dehydrate (AR, 90.0\%) were purchased from Macklin Reagent (Shanghai, China). Benzenesulfonic acid ( $\geq 90 \%$ ), dibenzothiophene $(\geq 98 \%)$ and tetradecane $(\geq 98 \%)$ were purchased from Aladdin Reagent (Shanghai, China). Phosphotungstic acid hydrate (AR) was purchased from Sinopharm Chemical Reagent Co. Ltd. (Shanghai, China). Iron(III) nitrate nonahydrate (AR) was purchased from BASF Chemical Reagent (Tianjin, China). All reagents were reagent grade and used as received.

\subsection{Preparation of POM catalyst and DESs}

$\mathrm{Na}_{3} \mathrm{Fe}(\mathrm{OH})_{6} \mathrm{Mo}_{6} \mathrm{O}_{18}$ was synthesized according to established procedures described elsewhere with minor modifications [51]. The synthesis of DESs was carried out by a simple mixing method. PEG2000 was selected as the donor and benzenesulfonic acid was selected as the acceptor. The donor and acceptor of the hydrogen bond were mixed according to molar ratios of $1 / 1,2 / 1,2.5 / 1$ and $3 / 1$. The two original components were vigorously stirred at $80{ }^{\circ} \mathrm{C}$ for $1 \mathrm{~h}$ using a magnetic stirrer in the oil bath.

\subsection{Characterization}

Fourier transform infrared (FT-IR) spectroscopy of the sample was performed on a Shimadzu IRAffinity-1S FT-IR spectrometer using $\mathrm{KBr}$ pellets at room temperature. The ultraviolet (UV) spectra were recorded on a TU-1901 (Beijing General Analytical Instrument Ltd Co, China) at room temperature. The oxidized diesel was tested by gas chromatography-flame photometric detector (GC-FPD) (Agilent 7890B; HP-5).

\subsection{Oxidative desulfurization of model diesel}

In a typical experiment, $4 \mathrm{~g}$ of DES was added to a three-necked flask, and $20 \mathrm{~mL}$ of model diesel with a sulfur content of $500 \mu \mathrm{g} \mathrm{g}^{-1}$ (DBT, BT and 4,6-DMDBT dissolved in the organic solvent decalin) was added. The extraction sample was taken at a constant temperature for $30 \mathrm{~min}$. Then $20 \mathrm{mg}$ of Fe-Anderson type POM was added and $60 \mathrm{ml} \mathrm{min}^{-1}$ of oxygen was bubbled from the bottom of the reactor. The upper oil phase of the reaction was sampled and analyzed by GC with flame ionization detector (GC-FID, Fuli 9750, HP-5). The sulfur content was measured using an internal standard method with tetradecane as the internal standard.

\section{Results and discussion}

\subsection{Effect of different desulfurization systems on DBT removal}

POMs catalysts with different structures have different catalytic effects on DBT removal. We investigated the desulfurization activity of Keggin-type $\mathrm{POM} \mathrm{H}_{3} \mathrm{PW}_{12} \mathrm{O}_{40}$, Anderson-type POM $\left(\mathrm{NH}_{4}\right)_{6} \mathrm{Mo}_{7} \mathrm{O}_{24}$ and $\mathrm{Na}_{3} \mathrm{Fe}(\mathrm{OH})_{6} \mathrm{Mo}_{6} \mathrm{O}_{18}$ (Table 1). It was found that the Keggin-type $\mathrm{POM} \mathrm{H}_{3} \mathrm{PW}_{12} \mathrm{O}_{40}$ catalyst exhibits very low removal of DBT (only 28\%) (Table 1, entry 3). In comparison to the low efficiency of Keggin-type POM catalysts, the Anderson-type POM $\left(\mathrm{NH}_{4}\right)_{6} \mathrm{Mo}_{7} \mathrm{O}_{24}$ catalysts show better catalytic activity. The removal of DBT can reach $63 \%$ within $1 \mathrm{~h}$ (Table 1, entry 1), which may be due to the fact that the Anderson-type POM has more terminal oxygen than the Keggin-type POM and is more susceptible to oxygen activation $[41,42,52]$. It is worth noting that the DBT removal of Anderson-type POM catalysts $\mathrm{Na} 3 \mathrm{Fe}(\mathrm{OH})_{6} \mathrm{Mo}_{6} \mathrm{O}_{18}$ reached $75 \%$. A possible reason for the different desulfurization activities may be the difference in the atomic center of the Anderson structure [53]. The composition of a DES plays an important role in its physicochemical properties $[21,27]$. The effect of the compositions of DESs on DBT extraction and oxidation was also studied (Table 1). BSA was chosen as HBD and PEG2000 was chosen as HBA. The AODS system exhibited very low desulfurization activity (29\% and $1 \%$, respectively) when either of the DES or POM was absent (Table 1, entries 4 and 5). To our surprise the removal of DBT was extremely high with DES $(n$ (HBDs) $/ n$ (HBAs) $=(1 / 2.5)$ (Table 1 , entry 8$)$, where DBT removal could reach $88 \%$ after 60 min of reaction, compared to $75 \%$ and $82 \%$ for $n(B S A) / n($ PEG2000) $=1 / 2$ and $1 / 3$ (Table 1 , entries 1 and 7), respectively. Moreover, when the DES composition $n(\mathrm{BSA}) / n(\mathrm{PEG} 2000)=1 / 1$ (Table 1 , entry 6), the desulfurization system shows the lowest extraction capacity, indicating that PEG2000 is a key component of DESs for extraction ability. Therefore, considering the desulfurization efficiency, $n(\mathrm{PEG} 2000) / n(\mathrm{BSA})=2.5 / 1$ was selected as the optimal molar ratio.

\subsection{Effect of the amount of catalyst on DBT removal}

The effect of the amount of catalyst on desulfurization is

Table 1

Effect of the different desulfurization systems on DBT removal.

\begin{tabular}{|c|c|c|c|c|}
\hline \multirow{2}{*}{ Entry } & \multirow{2}{*}{ Catalyst } & \multirow{2}{*}{$n(\mathrm{PEG} 2000) / n(\mathrm{BSA})$} & \multicolumn{2}{|c|}{ Sulfur removal (\%) } \\
\hline & & & EDS a & ECODS $\mathrm{b}$ \\
\hline 1 & $\mathrm{Na}_{3} \mathrm{Fe}(\mathrm{OH})_{6} \mathrm{Mo}_{6} \mathrm{O}_{18}$ & $2 / 1$ & 26 & 75 \\
\hline 2 & $\left(\mathrm{NH}_{4}\right)_{6} \mathrm{Mo}_{7} \mathrm{O}_{24}$ & $2 / 1$ & 25 & 63 \\
\hline 3 & $\mathrm{H}_{3} \mathrm{PW}_{12} \mathrm{O}_{40}$ & $2 / 1$ & 23 & 28 \\
\hline 4 & - & $2.5 / 1$ & 26 & 34 \\
\hline 5 & $\mathrm{Na}_{3} \mathrm{Fe}(\mathrm{OH})_{6} \mathrm{Mo}_{6} \mathrm{O}_{18}$ & - & - & 1 \\
\hline 6 & $\mathrm{Na}_{3} \mathrm{Fe}(\mathrm{OH})_{6} \mathrm{Mo}_{6} \mathrm{O}_{18}$ & $1 / 1$ & 17 & 53 \\
\hline 7 & $\mathrm{Na}_{3} \mathrm{Fe}(\mathrm{OH})_{6} \mathrm{Mo}_{6} \mathrm{O}_{18}$ & $3 / 1$ & 22 & 82 \\
\hline 8 & $\mathrm{Na}_{3} \mathrm{Fe}(\mathrm{OH})_{6} \mathrm{Mo}_{6} \mathrm{O}_{18}$ & $2.5 / 1$ & 27 & 87 \\
\hline
\end{tabular}


shown in Fig. 1. The DBT removal was studied with different amounts of catalysts of $0,5,10$, and $20 \mathrm{mg}$. Before the reaction, about 26\% DBT was transferred into the DES phase. The reactivity of the desulfurization system shows a trend of increasing first and then decreasing with an increasing amount of catalyst. When the amount of the catalyst is $5 \mathrm{mg}$, the desulfurization rate is only $69 \%$ in one hour. It is worth noting when $10 \mathrm{mg}$ of the catalyst dosage was used, the AODS system showed excellent activity and the removal of the sulfur-containing compound DBT could reach $95 \%$ after 60 min of reaction. This phenomenon can be attributed to the increase in the active site of the catalyst as the amount of the catalyst increases, resulting in a stronger reactivity. However, when the catalyst amount increased to $20 \mathrm{mg}$, DBT removal decreased from $95 \%$ to $87 \%$ in $60 \mathrm{~min}$. This behavior can be explained by the so-called "catalyst inhibitor conversion" phenomenon, which occurs in some oxidation reactions when the catalyst concentration is too high [53-56]. Thus, $10 \mathrm{mg}$ of the catalyst is considered to be the optimum amount for the catalytic oxidation system.

\subsection{Effect of dosage of DES on DBT removal}

A series of DBT removal experiments involving different DES dosages were carried out as shown in Fig. 2. With an increasing dosage of DES, a minimum of $13 \%$ and a maximum of $40 \%$ extraction desulfurization efficiency were obtained with the $1 \mathrm{~g}$ DES and the $10 \mathrm{~g}$ DES system, respectively. This result shows that the amount of DES is critical for the extraction capacity of this system. It was found that when the amount of DES is $4 \mathrm{~g}$, the desulfurization efficiency is the highest and reached $95 \%$ in $60 \mathrm{~min}$. But DBT removal was only $69 \%$ in $60 \mathrm{~min}$ compared to the $10 \mathrm{~g}$ DES system with the strongest extraction ability. This phenomenon may be owing to the excess DES having a dilution effect on the catalyst phase [57]. Therefore, $4 \mathrm{~g}$ of DES was considered to be the optimal dosage.

\subsection{Effect of reaction temperature on DBT removal}

The influence of temperature on DBT removal over the Fe-Anderson type catalyst $\mathrm{Na}_{3} \mathrm{Fe}(\mathrm{OH})_{6} \mathrm{Mo}_{6} \mathrm{O}_{18}$ was investigated

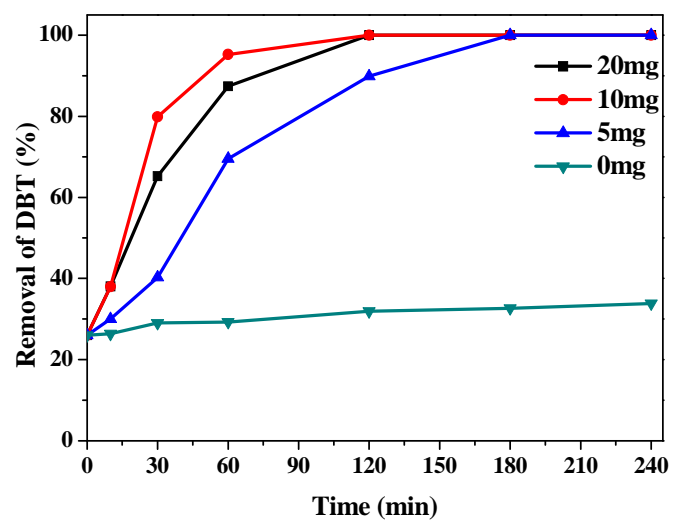

Fig. 1. Effect of dosage of catalyst on DBT removal. Experiment conditions: DES $(n(\mathrm{BSA}) / n(\mathrm{PEG} 2000)=1 / 2.5)=4 \mathrm{~g}, m$ (catalyst) $=(0,5,10$, 20) $\mathrm{mg}$, model oil (DBT) $=20 \mathrm{~mL}$, DBT (S: $\left.500 \mu \mathrm{g} \mathrm{g}^{-1}\right)$ in decalin, $60{ }^{\circ} \mathrm{C}$, oxygen flow rate $\left(60 \mathrm{~mL} \mathrm{~min}^{-1}\right)$.

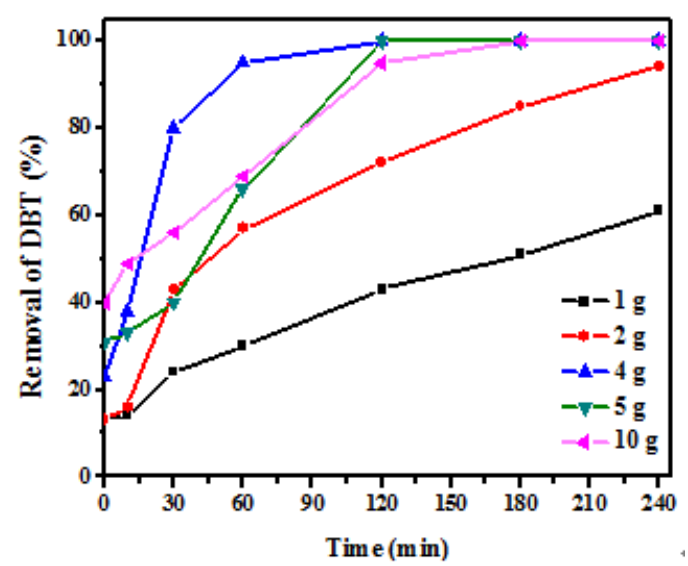

Fig. 2. Effect of dosage of DES on DBT removal. Experiment conditions: $\operatorname{DES}(n(\mathrm{BSA}) / n($ PEG2000 $)=1 / 2.5)=(1,2,4,5,10) \mathrm{g}, m$ (catalyst $)=10$ $\mathrm{mg}$, model oil (DBT) $=20 \mathrm{~mL}$, DBT (S: $500 \mu \mathrm{g} \mathrm{g}{ }^{-1}$ ) in decalin, $60^{\circ} \mathrm{C}$, oxygen flow rate $\left(60 \mathrm{~mL} \mathrm{~min}^{-1}\right)$.

in Fig. 3. When reaction temperatures were 40 and $50{ }^{\circ} \mathrm{C}$, DBT removal was only $14 \%$ and $34 \%$, respectively. With the increase in reaction temperature, the removal of DBT increased significantly, and a $95 \%$ removal of DBT was obtained at $60{ }^{\circ} \mathrm{C}$. It is worth noting that the removal of DBT can reach $100 \%$ at $70{ }^{\circ} \mathrm{C}$ in $60 \mathrm{~min}$. However, given economic and desulfurization efficiency factors, $60{ }^{\circ} \mathrm{C}$ was chosen in this work as the optimal temperature for the reaction.

\subsection{Effect of different S-compounds}

The reaction activity of different sulfur-compounds, for example, BT, DBT and 4,6-DMDBT in model diesel were studied in the AODS system (Fig. 4). It is worth noting that the removal of the two types of sulfur compounds DBT and 4,6-DMDBT can reach $99 \%$ in 180 min whereas the removal of BT reached $95 \%$ in $240 \mathrm{~min}$. The order of desulfurization activity is: DBT > 4,6-DMDBT > BT. In order to explore the reasons for their different desulfurization activities, the sulfur atoms and steric hindrance of three sulfur-containing compounds were ana-

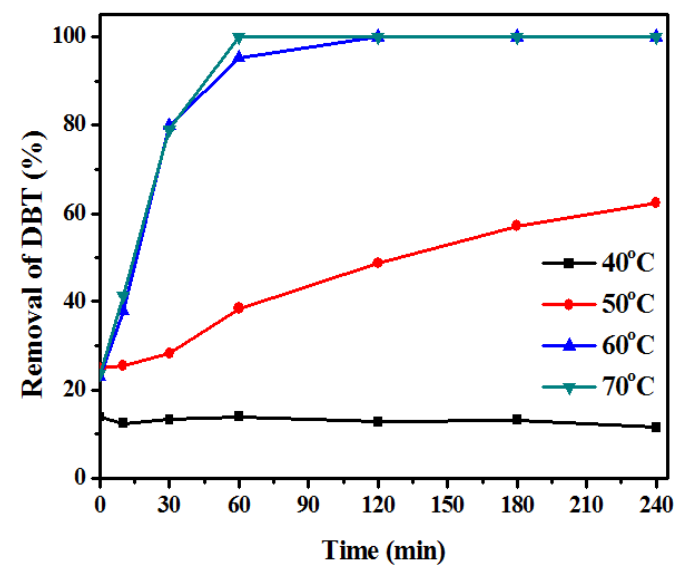

Fig. 3. Effect of reaction temperature on DBT removal. Experiment conditions: DES $(n(\mathrm{BSA}) / n($ PEG2000 $)=1 / 2.5)=4 \mathrm{~g}, m$ (catalyst $)=10$ mg, model oil $(\mathrm{DBT})=20 \mathrm{~mL}$, DBT $\left(\mathrm{S}: 500 \mu \mathrm{g} \mathrm{g}{ }^{-1}\right)$ in decalin, oxygen flow rate $\left(60 \mathrm{~mL} \mathrm{~min}^{-1}\right)$. 


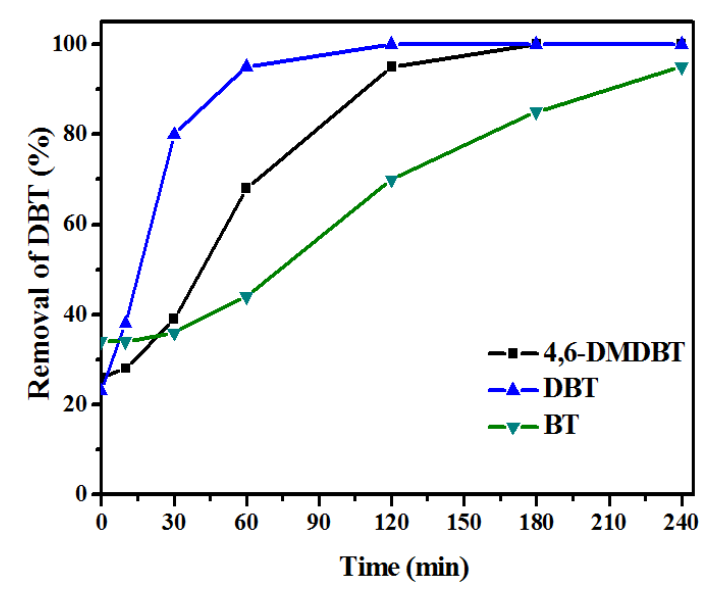

Fig. 4. Effect of different S-compounds. Experiment conditions: DES $(n(\mathrm{BSA}) / n(\mathrm{PEG} 2000)=1 / 2.5)=4 \mathrm{~g}, m$ (catalyst $)=10 \mathrm{mg}$, model oil $(\mathrm{DBT})=20 \mathrm{~mL}$ (DBT, BT, 4-MDBT, 4,6-DMDBT) (S: $\left.500 \mu \mathrm{g} \mathrm{g}^{-1}\right)$ in decalin, $60^{\circ} \mathrm{C}$, oxygen flow rate $\left(60 \mathrm{~mL} \mathrm{~min}^{-1}\right)$.

lyzed. BT has the lowest electron density (5.696), so its AODS process has the lowest activity [58]. However, the difference in electron density between DBT and 4,6-DMDBT (5.758 and 5.760 , respectively) is negligible, and the difference in AOSD process activity can be attributed to the effect of steric hindrance [59]. This hypothesis is consistent with the results of our previous work [56].

\subsection{Commercial diesel experiments}

The application of biomimetic AODS systems in real diesel was also investigated. Figs. 5 and 6 show GC analysis profiles of sulfur-containing compounds in two kinds of commercial diesel (abbreviated as Commercial Diesel I and II) before and after desulfurization, respectively. After desulfurization of Commercial Diesel I, the content of sulfur compounds in the diesel oil was reduced from 24 to $3 \mu \mathrm{g} \mathrm{g}^{-1}$ (desulfurization rate $88 \%$, Table 2, entry 1). Furthermore, the sulfur content of Commercial Diesel II after desulfurization was reduced to only $59 \mu \mathrm{g} \mathrm{g}-1$ (Table 2, entry 2). It can be seen from Fig. 5 that most of the remaining sulfur content is due to unoxidized BT and its deriv-

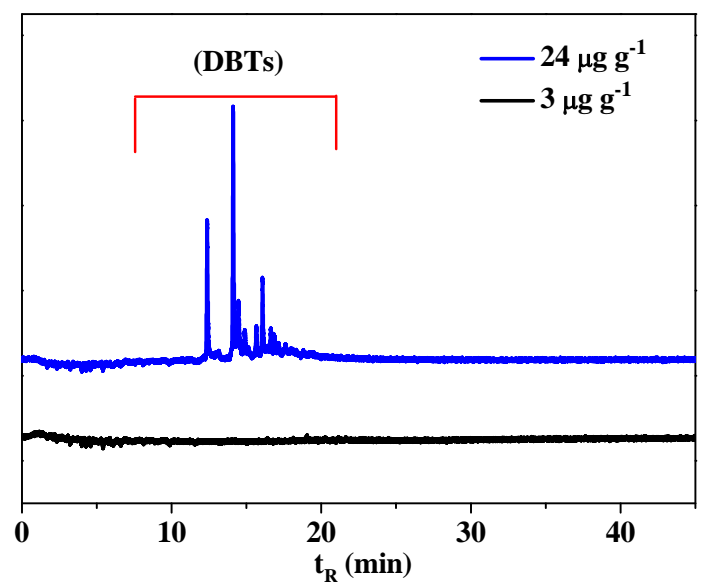

Fig. 5. GC-FPD chromatograms of commercial diesel I before and after oxidation.

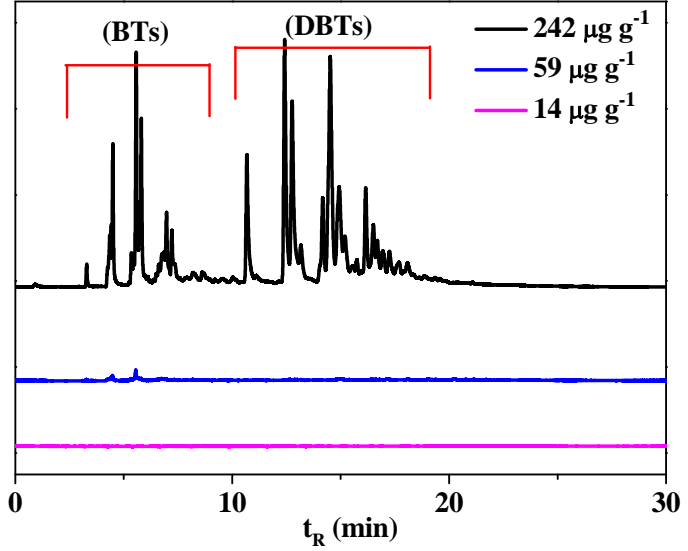

Fig. 6. GC-FPD chromatograms of commercial diesel II, before oxidation after the first oxidation, and after the secondary oxidation.

atives. So the obtained Commercial Diesel II was subjected to a second AODS treatment. After the secondary desulfurization of Commercial Diesel II, the remaining sulfur content was $14 \mu \mathrm{g}$ $\mathrm{g}^{-1}$ and the total desulfurization reached $94 \%$ (Table 2, entry 2). The result is consistent with the reaction activity results of different sulfur compounds (Fig. 4, BT was more difficult to remove than DBT in this system). The results also indicate that the biomimetic AODS system can be used for real diesel.

\subsection{Recycling experiments}

In order to detect the stability of DES containing the Fe-Anderson type catalyst, a recovery experiment was carried out as shown in Fig. 7. The system after the reaction was allowed to stand overnight, and then the upper oil was separated from the reaction system by decantation. Therefore, the biomimetic system (the low DES phase containing POM) was recovered and then the fresh model diesel added into it for the next AODS process under the same conditions. The biomimetic AODS system showed no significant decrease in activity after 5 cycles, confirming its good stability.

\subsection{Mechanism studies}

To investigate the effect of DES physical properties on the desulfurization efficiency of diesel, the conductivity and viscosity of different DESs were tested. It can be seen in Fig. 8 that the conductivity of DES decreases with an increase in the amount of PEG2000 amount at a certain temperature. According to the experimental results (Table 1, entries 1,6, 7 and 8), the solvent conductivity of DES was not the main factor affecting the

Table 2

Aerobic oxidation of sulfur compounds in commercial diesel.

\begin{tabular}{lccc}
\hline \multirow{2}{*}{ Diesel } & \multicolumn{2}{c}{ Sulfur content $\left(\mu \mathrm{g} \mathrm{g}^{-1}\right)$} & $\begin{array}{c}\text { Sulfur removal } \\
(\%)\end{array}$ \\
\cline { 2 - 3 } & Original diesel & AODS diesel a & 88 \\
\hline $\mathrm{I}$ & 24 & 3 & 94 \\
$\mathrm{II}$ & 242 & 14 & $\mathrm{~m}$ \\
\hline a Commercial diesel $=10 \mathrm{~mL}, \mathrm{DES}=10 \mathrm{~g}, T=60{ }^{\circ} \mathrm{C}, t=240 \mathrm{~min}$, \\
$m$ (catalyst) $=20 \mathrm{mg}$, oxygen flow rate $\left(60 \mathrm{~mL} \mathrm{~min}^{-1}\right)$.
\end{tabular}




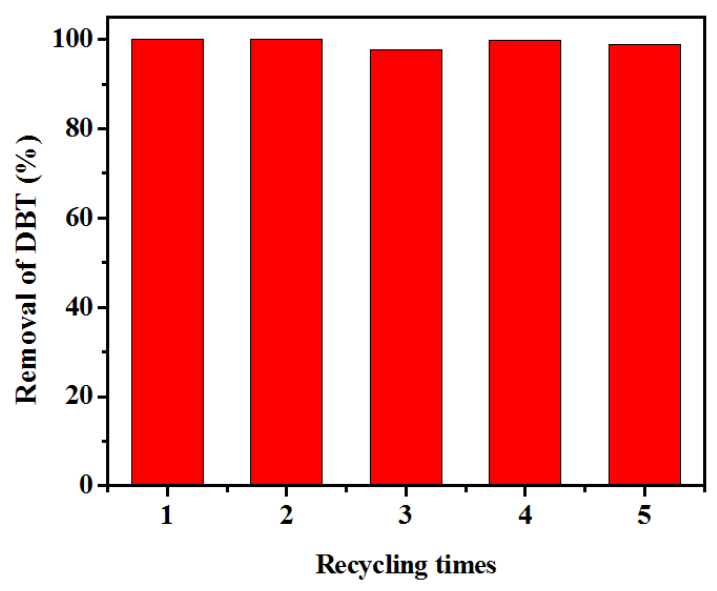

Fig. 7. Effect of recycling of catalyst on DBT removal. Experiment conditions: $T=60^{\circ} \mathrm{C}, \mathrm{DES}=4 \mathrm{~g}$, catalyst $=10 \mathrm{mg}$, model oil $(\mathrm{DBT})=20 \mathrm{~mL}$, DBT (S: $500 \mu \mathrm{g} \mathrm{g}^{-1}$ ) in decalin.

desulfurization reactivity of the system. This means that it could not be simply concluded that the correlation between the conductivity of DES and desulfurization capability was positive or negative. Fig. 9 shows the viscosity data of DESs of different compositions at different temperatures. PEG2000/2.5BSA has a maximum viscosity of $60{ }^{\circ} \mathrm{C}$ and was speculated to have a stronger hydrogen bond, because viscosity data is mainly affected by intermolecular hydrogen bonding at low temperatures $[60,61]$. What is particularly noteworthy is that PEG2000/2.5BSA was also the best system for AODS activity (Table 1). Therefore, we speculate that the activity of the biomimetic AODS system is related to the hydrogen bond strength between the DES components. This conclusion is consistent with the results of our previous work [27]. When the temperature was raised to $80{ }^{\circ} \mathrm{C}$, the viscosity increased when the composition of PEG 2000 increased. Because of the high temperature, the stacking effect plays a dominant role. The longer the carbon chain of the compound, the stronger the filling effect and the more difficult the free movement, so the viscosity of the liquid increases as the length of the carbon chain increases $[60,61]$.

The UV-visible (UV-Vis) spectrum of Fe-Anderson catalyst dissolved in acetonitrile varies in the presence of nitrogen or molecular oxygen, as shown in Fig. 10a. The disappearance of

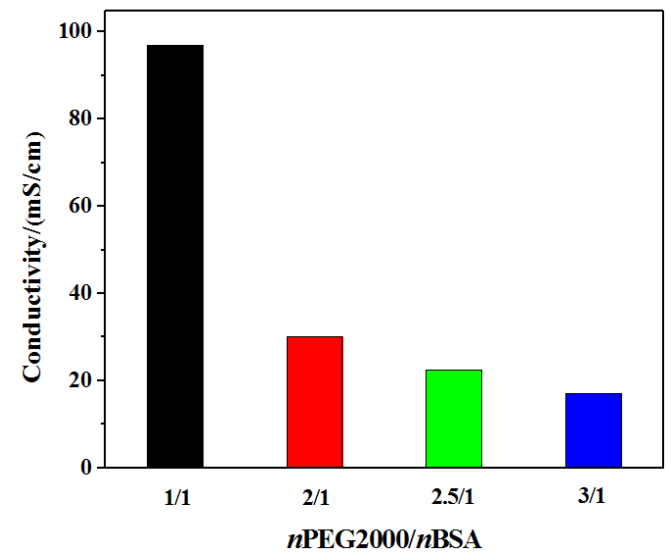

Fig. 8. Conductivity maps of different compositions of DES at $60^{\circ} \mathrm{C}$.

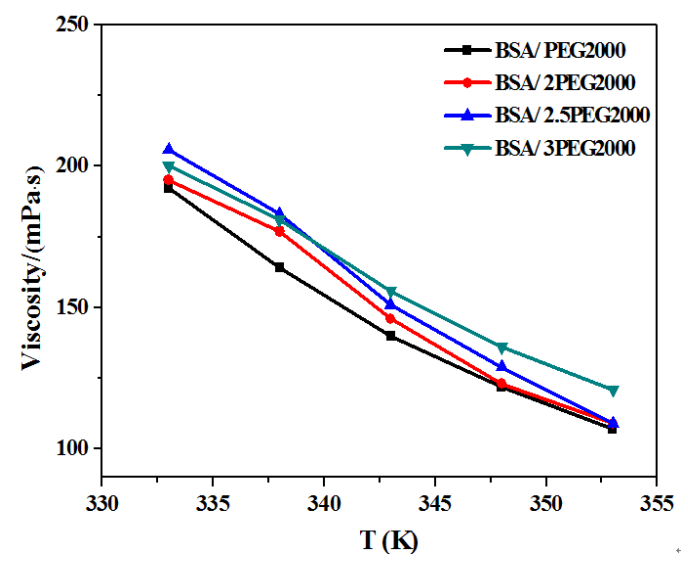

Fig. 9. Relationship between viscosity and temperature of DES.

the absorption peaks at 232 and $258 \mathrm{~nm}$ indicates that Fe-Anderson catalyst interacts with oxygen [42]. The UV-vis spectrum of BSA-based DES dissolved in acetonitrile showed little change in the presence of nitrogen or molecular oxygen. However, when the Fe-Anderson catalyst was added to the DES-containing acetonitrile solution as shown in Fig. 10b, the peaks at 232 and $258 \mathrm{~nm}$ disappeared markedly after oxygen bubbling for $1 \mathrm{~h}$. This implied that oxygen cannot directly form peroxosulfonate with BSA due to the high energy barrier, but oxygen molecules can be activated when POM and DES coexist [50]. These results are consistent with the experimental observation that the desulfurization system is inactive when POM and DES were used alone, but a high AODS activity could be obtained when POM and DES were used together. (Table 1, entries 4 and 5). In order to further verify the reaction mechanism, the Fourier-transform infrared (FT-IR) spectra of DES and POM in an oxygen or nitrogen atmosphere were investigated. Infrared curves of DES and POM under nitrogen atmosphere are shown in Fig. 11a. The three absorption peaks at 1118, 1145 and $1199 \mathrm{~cm}^{-1}$ are attributed to the $\mathrm{SO}_{2}$ stretching vibration [32], and the 870-1000 absorption peaks are assigned to POM [42]. It is worth noting that when DES and POM reacted in the oxygen environment for $60 \mathrm{~min}$ (Fig. 11b), the absorption peaks of 1118 and $1199 \mathrm{~cm}^{-1}$ moved to 1110 and $1176 \mathrm{~cm}^{-1}$ respectively, and the changes in these two absorption peak positions indicate that sulfonic acid groups form new species under the action of oxygen.

Moreover, a new absorption peak is generated at $963 \mathrm{~cm}^{-1}$, possibly because the heteropolyanion of POM interacts with oxygen to form a peroxopolyanion [62]. The IR results were consistent with the UV characterization and confirmed the formation of peroxosulfonate. Based on the results of UV-vis, FT-IR and GC-mass spectrometry (GC-MS) (see SI), we speculated about the mechanism of AODS by multistep electron transfer through a biomimetic approach (Scheme 1). First, POM and oxygen form peroxopolyacid anions, which then undergo nucleophilic substitution with benzenesulfonic acid in the protic solvent PEG2000 to form phenylperoxysulfonic acid. Because peroxysulfonate is highly active for electron-rich $\mathrm{S}$ atoms, it preferentially attacks the S atom. Thereby, DBT is oxidized to $\mathrm{DBTO}_{2}$. The reduced phenylperoxysulfonic acid and POMs are 

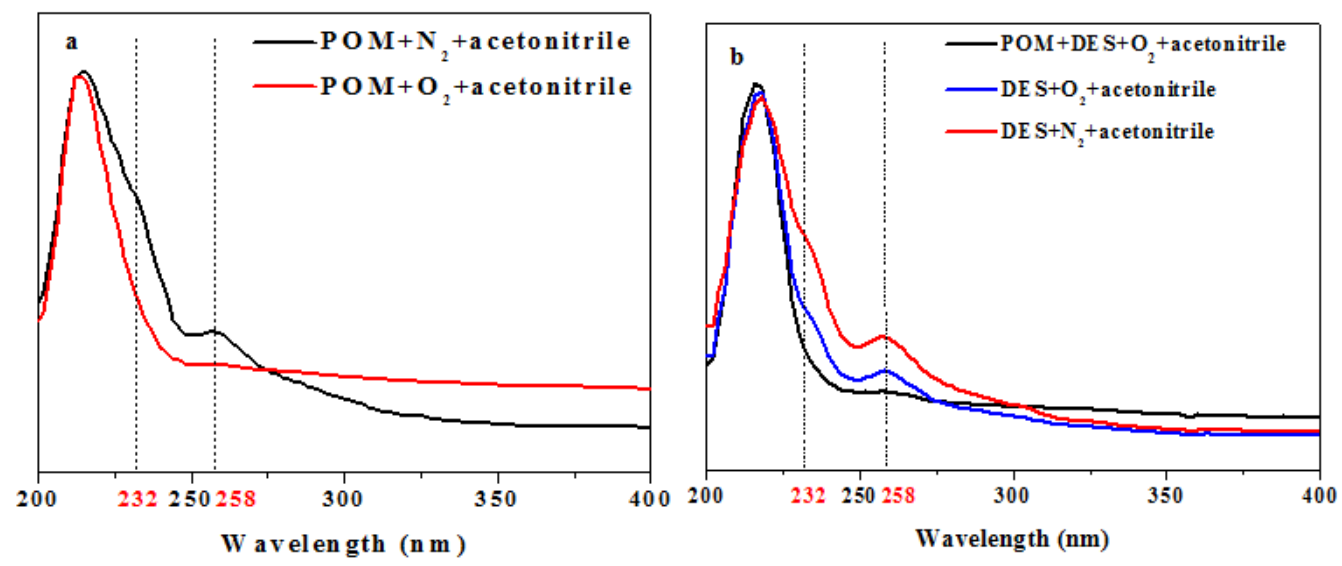

Fig. 10. UV-vis spectra of $\mathrm{Na}_{3} \mathrm{H}_{6} \mathrm{FeMo}_{6} \mathrm{O}_{24}$ with DESs in acetonitrile.

oxidized by $\mathrm{O}_{2}$ to initiate a new catalytic cycle. These results indicate that the coupled redox system and ETMs facilitate the reaction process by transporting electrons from the BSA-based DES to the oxidant along a low energy pathway. Eventually, the DBT was susceptible to oxidation to $\mathrm{DBTO}_{2}$.

\section{Conclusions}

A new Fe-Anderson catalyst coupled with a PEG2000/BSA-type DES biomimetic system has been successfully prepared. The viscosity of DES is maximum in the $n(\mathrm{PEG} 2000) / n(\mathrm{BSA})=2.5$ system at $60^{\circ} \mathrm{C}$, and it is speculated

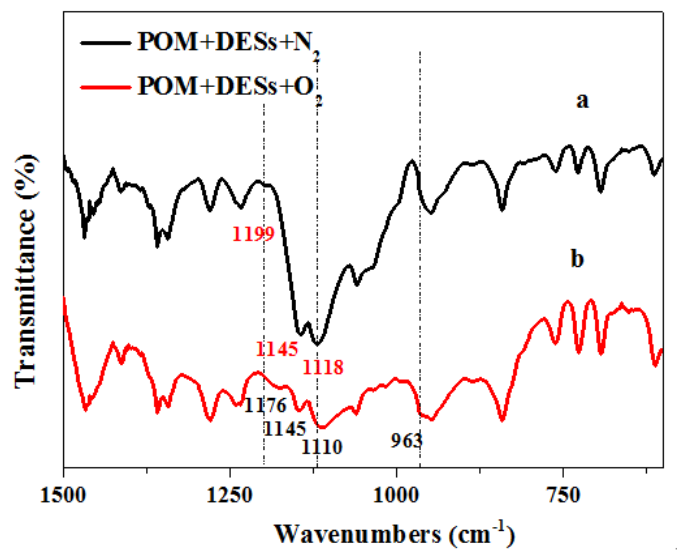

Fig. 11. IR spectra of $\mathrm{Na}_{3} \mathrm{H}_{6} \mathrm{FeMo}_{6} \mathrm{O}_{24}$ and DES in $\mathrm{O}_{2}$ and $\mathrm{N}_{2}$ atmospheres.

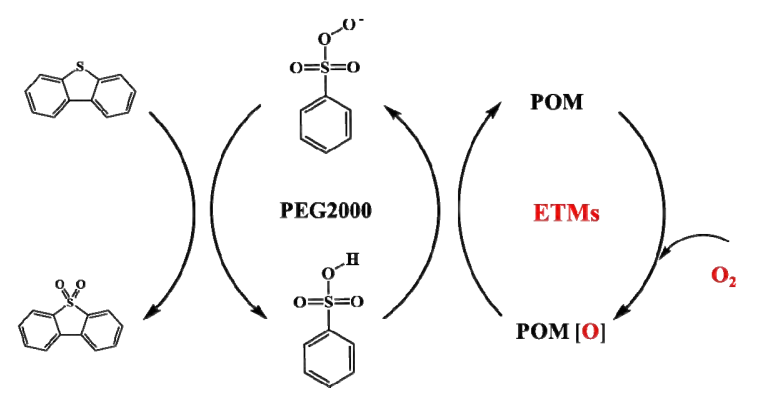

Scheme 1. Speculation on the mechanism of extracting and oxidizing DBT. that this results from stronger hydrogen bonding. In addition, the PEG2000/2.5BSA system also possesses the best desulfurization activity. This result suggests that the activity of the desulfurization system is related to the strength of the hydrogen bonding. This biomimetic strategy was applied to AODS of model diesel, showing unprecedented performance with $95 \%$ removal of DBT in 60 min. Furthermore, this biomimetic system can also be successfully used for oxidative desulfurization of real diesel. Finally, the catalyst can be recycled 5 times without a significant decrease in reactivity, indicating the potential for commercial use of this catalytic system.

\section{References}

[1] R. P. Gupta, B. S. Turk, J. W. Portzer, D. C. Cicero, Environ. Prog., 2001, 20, 187-195.

[2] R. T. Yang, A. J. Hernández-Maldonado, F. H. Yang, Science, 2003, 301, 79-81.

[3] D. Zhao, J. Wang, E. Zhou, Green Chem., 2007, 9, 1219-1222.

[4] J. M. Campos-Martin, M. C. Capel-Sanchez, P. Perez-Presas, J. L. G. Fierro, J. Chem. Technol. Biotechnol., 2010, 85, 879-890.

[5] A. Mansouri, A. A. Khodadadi, Y. Mortazavi, J. Hazard. Mater., 2014, 271, 120-130.

[6] W. H. Lo, H. Y. Yang, G. T. Wei, Green Chem., 2003, 5, 639-642.

[7] H. Xu, D. Zhang, F. Wu, R. Cao, Fuel, 2017, 208, 508-513.

[8] Y. Tian, Y. Yao, Y. Zhi, L. Yan, S. Lu, Energy Fuels, 2015, 29, 618-625.

[9] D. Yan, J. Xin, C. Shi, X. Lu, L. Ni, G. Wang, S. Zhang, Chem. Eng. J., 2017, 323, 473-482.

[10] D. Yan, J. Xin, Q. Zhao, K. Gao, X. Lu, G. Wang, S. Zhang, Catal. Sci. Technol, 2018, 8, 164-175.

[11] Q. Zhang, K. De Oliveira Vigier, S. Royer, F. Jérôme, Chem. Soc. Rev., 2012, 41, 7108-7146.

[12] I. M. Aroso, A. Paiva, R. L. Reis, A. R. C. Duarte, J. Mol. Liq., 2017, 241, 654-661.

[13] A. R. R. Teles, E. V. Capela, R. S. Carmo, J. A. P. Coutinho, A. J. D. Silvestre, M. G. Freire, Fluid Phase Equilib., 2017, 448, 15-21.

[14] H. Ren, S. Lian, X. Wang, Y. Zhang, E. Duan, J. Cleaner Prod., 2018, 193, 802-810.

[15] S. Wang, P. Li, L. Hao, C. Deng, W. Ren, H. Lü, Chem. Eng. Technol., 2017, 40, 555-560.

[16] L. Zhang, J. Wang, Y. Sun, B. Jiang, H. Yang, Chem. Eng. J., 2017, 328, 


\section{Graphical Abstract}

Chin. J. Catal., 2020, 41: 868-876 doi: S1872-2067(19)63500-X

\section{Green aerobic oxidative desulfurization of diesel by constructing an Fe-Anderson type polyoxometalate and benzene sulfonic acid-based deep eutectic solvent biomimetic} cycle

Jiajia Xu, Zhiguo Zhu, Ting Su, Weiping Liao, Changliang Deng, Dongmei Hao*, Yuchao Zhao, Wanzhong Ren, Hongying Lü* Yantai University

A unique redox-coupled biomimetic system was developed, in which Fe-Anderson type polyoxometalates (POMs) were employed as electron transfer mediators (ETMs) and benzenesulfonic acid (BSA)-based deep eutectic solvents (DESs) were used as the electron-donors for aerobic oxidative desulfurization (AODS) of diesel fuel.

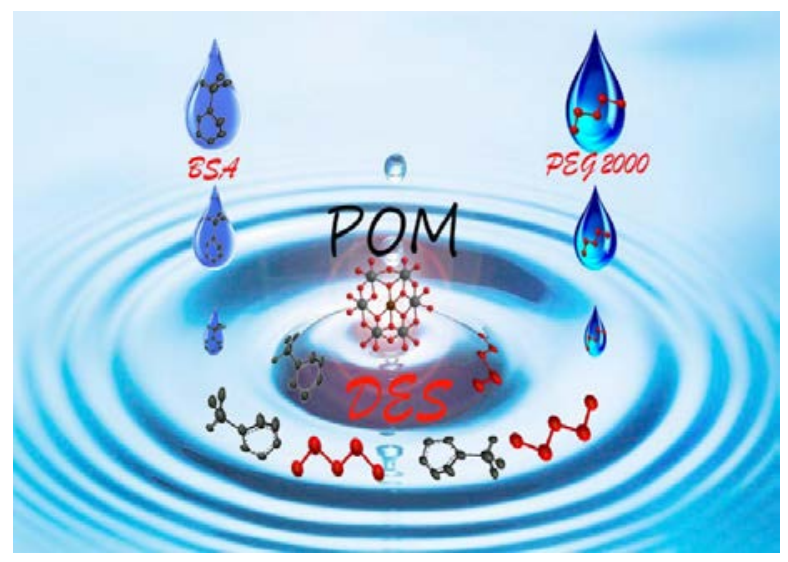

[35] A. M. Khenkin, R. Neumann, ChemSusChem, 2011, 4, 346-348.

[36] P. Wu, W. Zhu, Y. Chao, J. Zhang, P. Zhang, H. Zhu, C. Li, Z. Chen, H. Li, S. Dai, Chem. Commun., 2016, 52, 144-147.

[37] P. Wu, W. Zhu, B. Dai, Y. Chao, C. Li, H. Li, M. Zhang, W. Jiang, H. Li, Chem. Eng. J., 2016, 301, 123-131.

[38] X. Yao, C. Wang, H. Liu, H. Li, P. Wu, L. Fan, H. Li, W. Zhu, Ind. Eng. Chem. Res., 2019, 58, 863-871.

[39] W. Zhu, C. Wang, H. Li, P. Wu, S. Xun, W. Jiang, Z. Chen, Z. Zhao, H. Li, Green Chem., 2015, 17, 2464-2472.

[40] S. Omwoma, C. T. Gore, Y. Ji, C. Hu, Y. F. Song, Coord. Chem. Rev., 2014, 286, 17-29.

[41] H. Lü, Y. Zhang, Z. Jiang, C. Li, Green Chem., 2010, 12, 1954-1958.

[42] H. Lü, W. Ren, W. Liao, W. Chen, Y. Li, Z. Suo, Appl. Catal. B, 2013, 138-139, 79-83.

[43] S. Oae, T. Takata, Tetrahedron Lett., 1980, 21, 1-4.

[44] R. Kluge, M. Schulz, G. Strabe, Tetrahedron, 1996, 52, 2957-2976.

[45] M. Schulz, S. Liebsch, R. Kluge, W. Adam, J. Org. Chem., 2002, 62, 188-193.

[46] J. Piera, J. Bäckvall, Angew. Chem. Int. Ed., 2008, 47, 3506-3523.

[47] P. Gouzerh, A. Proust, Chem. Rev., 1998, 98, 77-112.

[48] M. Zhao, X. Zhang, C. Wu, ACS Catal., 2017, 7, 6573-6580.

[49] B. P. Babu, X. Meng, J.-E. Bäckvall, Chem. Eur. J., 2013, 19, $4140-4145$.

[50] L. Sun, T. Su, J. Xu, D. Hao, W. Liao, Y. Zhao, W. Ren, C. Deng, H. Lü, Green Chem., 2019, 21, 2629-2634

[51] A. Blazevic, E. Al-Sayed, A. Roller, G. Giester, A. Rompel, Chem.-Eur. J., 2015, 21, 4762-4771.

[52] H. Ji, J. Sun, P. Wu, B. Dai, Y. Chao, M. Zhang, W. Jiang, W. Zhu, H. Li, J. Mol. Catal. A, 2016, 423, 207-215.

[53] H. Lü, W. Ren, P. Liu, S. Qi, W. Wang, Y. Feng, F. Sun, Y. Wang, Appl. Catal. A, 2012, 441-442, 136-141.

[54] C. Guo, Q. Liu, X. T. Wang, H. Y. Hu, Appl. Catal. A, 2005, 282, 55-59.

[55] J. F. Black, J. Am. Chem. Soc., 1978, 100, 527-535.

[56] H. Lü, P. Li, Y. Liu, L. Hao, W. Ren, W. Zhu, C. Deng, F. Yang, Chem. Eng. J., 2017, 313, 1004-1009.

[57] W. Jiang, L. Dong, W. Liu, T. Guo, H. Li, M. Zhang, W. Zhu, H. Li, RSC 
Adv., 2017, 7, 55318-55325.

[58] H. Li, W. Zhu, S. Zhu, J. Xia, AIChE J., 2016, 62, 2087-2100.

[59] H. Lü, W. Ren, H. Wang, Y. Wang, W. Chen, Z. Suo, Appl. Catal. A, 2013, 453, 376-382.

[60] A. Pinkert, K. N. Marsh, S. Pang, M. P. Staiger, Chem. Rev., 2009,
$109,6712-6728$.

[61] H. Wang, G. Gurau, R. D. Rogers, Chem. Soc. Rev., 2012, 41, 1519-1537.

[62] J. Gao, Y. Chen, B. Han, Z. Feng, C. Li, N. Zhou, S. Gao, Z. Xi, J. Mol. Catal. A, 2004, 210, 197-204.

\title{
Fe-Anderson型多金属氧酸盐和苯磺酸基低共熔溶剂仿生体系的构建 及其柴油绿色氧化脱硫
}

\author{
徐佳佳 ${ }^{\mathrm{a}}$, 朱志国 ${ }^{\mathrm{a}}$, 苏 婷 ${ }^{\mathrm{a}}$, 廖卫平 ${ }^{\mathrm{a}}$, 邓昌亮 ${ }^{\mathrm{a}}$, 郝冬梅, , , \#, 赵玉潮 ${ }^{\mathrm{a}, \mathrm{c}}$, 任万忠 ${ }^{\mathrm{c}}$, 吕宏缨 ${ }^{\mathrm{a}}$, \\ a烟台大学化学化工学院绿色化学中心, 山东烟台 264005 \\ b烟台大学土木工程学院, 山东烟台 264005 \\ c烟台大学化学化工学院轻烃转化利用协同创新中心, 山东烟台264005
}

\begin{abstract}
摘要: 在过去的几十年里, 人们越来越关注环境污染问题. 柴油中的硫化物燃烧后可转化为 $\mathrm{SO}_{\mathrm{x}}$, 对环境造成严重污染. 因 此, 为了满足严格的国家标准要求, 生产硫化物含量极低的燃料油是一个巨大挑战. 氧化脱硫(ODS)体系是用于深度脱硫 的加氢脱硫(HDS)体系的替代或补充, 包括硫化物的氧化和氧化产物的分离. 它是处理芳香硫化合物及其衍生物最有效的 方法之一, 引起了人们的极大关注. 在我们之前的工作中报道了Co聚阴离子催化剂和对甲苯磺酸基低共熔剂(DESs)通过 仿生方法将柴油中的硫化物氧化为相应的硫化物. 尽管已经取得了很大的进展, DESs仿生体系仍然有很大的发展空间. 例如, 多金属氧酸盐(POMs)在生物模拟体系中的作用没有得到明确阐述. 更困难的是构建DES的物理化学性质与仿生体 系氧化脱硫效率之间的关系. 因此, 解决上述问题是催化氧化脱硫(AODS)仿生过程中最关键的挑战之一, 迫切需要进一步 研究.

本文采用仿生方法研究了一种新型高效的AODS体系, 该体系能显著提高ODS的效率. 采用重结晶法制备了安德森型 催化剂 $\mathrm{Na}_{3} \mathrm{Fe}(\mathrm{OH})_{6} \mathrm{Mo}_{6} \mathrm{O}_{18}$, 并将其应用于柴油AODS体系. 通过分析紫外-可见光谱(UV-Vis)、红外光谱(FT-IR)以及气质联 用光谱(GC-MS), 我们推测了通过多步电子转移AODS体系的仿生机理. 首先, POM和氧气形成过氧聚阴离子, 然后与苯磺 酸形成苯基过氧磺酸. 由于过氧磺酸盐对富电子的硫原子具有很高的选择性, 所以它优先攻击硫原子. 因此, 二苯并噻吩 被氧化成二苯并噻吩砜. 还原后的苯磺酸和POM被氧气氧化, 形成新的催化循环. 这些结果表明, 耦合氧化还原体系和 ETMs 通过低能量途径将电子从苯磺酸基DES转移到氧化剂, 从而促进了反应过程. 最终, 二苯并噻吩易被氧化为二苯并噻 吩砜.

DES的物理性质表明, 在 $60^{\circ} \mathrm{C}$ 时, $n(\mathrm{PEG} 2000) / n(\mathrm{BSA})=2.5$ 体系中DES粘度最大, 推测可能是氢键较强所致. 此外, PEG2000/2.5BSA体系脱硫效果也是最好的. 这一结果表明, 脱硫体系的活性与氢键的强度有关. 将该仿生策略应用于模 型柴油的AODS中, 在 $60 \mathrm{~min}$ 内二苯并噻吩脱除率达到 $95 \%$, 表现出前所未有的性能, 并且该仿生体系也可以成功应用于真 实柴油的氧化脱硫. 该催化剂可重复使用五次, 且反应活性无明显降低, 表明该催化体系具有商业应用潜力.
\end{abstract}

关键词: 催化氧化脱硫; Fe-Anderson型多金属氧酸盐; 低共熔剂; 二苯并噻吩; 物理性质; 电子转移介质

收稿日期: 2019-11-12. 接受日期: 2019-12-14. 出版日期: 2020-05-05.

*通讯联系人. 电话/传真: (0535)6902603; 电子信箱: hylv@ytu.edu.cn

\#通讯联系人.电子信箱: qgzx@ytu.edu.cn

基金来源：国家自然科学基金(21676230, 21373177).

本文的电子版全文由Elsevier出版社在ScienceDirect上出版(http://www.sciencedirect.com/science/journal/18722067). 